\title{
Ineffable Cultures or Material Devices: What Valuation Studies can Learn from the Disappearance of Ensured Solidarity in a Health Care Market
}

\author{
Teun Zuiderent-Jerak and Stans van Egmond
}

\begin{abstract}
Valuation studies addresses how values are made in valuation practices. A next -or rather previous-question becomes: what then makes valuation practices? Two oppositional replies are starting to dominate how that question can be answered: a more materially oriented focus on devices of valuation and a more sociologically inclined focus on ineffable valuation cultures. The debate between proponents of both approaches may easily turn into the kind of leapfrog debates that have dominated many previous discussions on whether culture or materiality would play a decisive role in driving history. This paper explores a less repetitive reply. It does so by analyzing the puzzling case of the demise of solidarity as a core value within the recent Dutch health care system of regulated competition. While "solidarity among the insured" was both a strong cultural value within the Dutch welfare-based health system, and a value that was built into market devices by health economists, within a fairly short time "fairness" became of lesser importance than "competition". This makes us call for a more historical, relational, and dynamic understanding of the role of economists, market devices, and of culture in valuation studies.
\end{abstract}

Key words: culture; devices; social studies of markets; sociology of economic valuation; health care markets; performativity

Teun Zuiderent-Jerak, Department of Thematic Studies-Technology and Social

Change, Linköping University, teun.zuiderent-jerak@liu.se

Stans van Egmond, Dutch Thrombosis Foundation, Voorschoten, c.vanegmond@trombosestichting.nl

(C) 2015 Teun Zuiderent-Jerak and Stans van Egmond.

LiU Electronic Press, DOI 10.3384/VS.2001-559.153145

http://valuationstudies.liu.se 
Culture: "At last we meet again;

Hadn't I scared you off for good?"

Device: "I'm good at hiding from the grand; That's what you never understood!"

Culture: "What is the fight we'll pick today?

Those bridges seem to get revived!"1

Device: "Please not again! I'm victor there. My politics beyond surmised!"

Culture: "It's really not, but ... let's take bikes.

There it is clear that I make you!"2

Device: "How stale, repetitive you are! Can't you come up with something new?!"

Culture: "It's new you want? Well, Values then;

The stakes couldn't be further raised!"

Device: "An easy one; values I make;

Such has been shown, case after case."

Culture: “That's only 'cause you don't compare!

Beyond the case, 'tis I who rule."

Device: "Well, let us make this interesting;

A welfare market's hard to fool..."

${ }^{1}$ The classic debate on the role of Moses' bridges in materializing the politics of discrimination (against minorities by being too low (or not!) for buses to pass underneath them, making the beaches of Long Island inaccessible to those not traveling by car) is perhaps one of the best known examples of an exploration of the relationship between artifacts and politics/culture (Joerges 1999; Winner 1980; Woolgar and Cooper 1999). The positions presented in this debate are highly similar to the ones that will appear in this article as it unfolds. The continued relevance of such debates is shown by its revival in a recent documentary on the presumed politics of those bridges (see http://www.cca.qc.ca/en/education-events/2518misleading-innocence-tracing-what-a-bridge-can-do).

2 Wiebe Bijker's study of how bicycles got shaped by relevant social groups is another renowned case of varying positions on the dynamics between culture and technology (Bijker 1995). The fairly unidirectional influence of social groups on technology design that sets out Social Construction of Technology (SCOT) from more radically constructivist theories has been criticized for failing to address material constraints and agency (Jasanoff 2004) and has been classified as 'social determinism' (Hughes 1994). 


\section{Introduction: If Values Are Made in Valuation Practices, How Are Valuation Practices Made?}

The development of market arrangements in public sectors within welfare states is an attractive site for valuation studies. Empirically, this topic is surely not understudied: public sector reforms within the paradigm of "the market" as a solution for the perceived ineffectiveness of the public sector have been analyzed and criticized by many. ${ }^{3}$ Such criticisms have traditionally focused on market logics and the suitability-or lack thereof-of competitive arrangements to address public concerns: the market would infringe upon public values in ways that need to be empirically shown. In contrast, scholars in the emerging field of valuation studies turn markets for public goods into the empirical study of public values as practical accomplishments that play out differently in a wide array of valuation practices (Dussauge et al. 2015). Precisely the often sticky and repetitive narratives about the contrast between "the market" and "public values" in fields like public administration, makes markets for public goods an attractive topic for the study of valuation.

This shift to the study of how valuation practices shape rather than implement or obstruct public values, gives rise to a next-or rather previous-question: what, in turn, actually makes valuation practices? Here valuation studies draws extensively on sensitivities from two of its "mother disciplines": economic sociology and science and technology studies (STS). Taking inspiration from economic sociology, scholars tend to seek to explain valuation practices that are made in social and cultural arrangements and that in turn make certain forms of valuation more likely than others (Boltanski and Chiapello 2005). Drawing on STS sensitivities about the role of devices in the construction of the social, other scholars are attending closely to the role of (market) devices (Callon et al. 2007) and economic theories (MacKenzie et al. 2007) in the shaping of valuation practices.

Tensions between these two possible answers to the question "if values are made in valuation practices, what makes those valuation practices?" produce something of a leapfrog academic debate on valuation studies in relation to markets for public values. Economic sociologists take the importance of cultural embedding as a starting point. Culture's importance ties in neatly with the need for comparative analysis, which then leads to the empirical finding that "culture matters". In contrast, social studies of markets scholars, starting from STS sensitivities about the performativity of (economic) scientists and

3 See e.g. Balle Hansen and Lauridsen 2004; Hunter 2005; Pierson 1994, 2004; Porter and Olmsted Teisberg 2004; Ranade 1995; Walsh 1995, and others. 
(market) devices, carry out detailed case studies of individual market making practices in which they discover that economists and devices matter for the development of markets.

In this article, we want to take the reader on a journey that leads through a somewhat less parceled scholarly landscape. We rather want to show, based on our scholarly background in STS, how we started out studying the role of health economists and market devices in the construction of the Dutch health care market, but found that the role of these scientists and their devices changed substantially over time. Where initially they seemed rather successful in enacting a health care market that safeguarded the widely held cultural value of solidarity about access to and quality of health care, we found that over time health economists increasingly faced a cultural shift toward prioritizing the value of competition over solidarity. The point we want to make here is that this shift can neither be explained by focusing on economic devices enacting competition over solidarity, nor through a lack of cultural embedding of those devices in a culture that was in fact about competition: the devices and the cultural values that both initially aimed at prioritizing solidarity over competition, were equally unsuccessful over time.

Don't worry! We will not be presenting an even grander explanation toward the end of this article-one that "underlies" or "hovers over" both devices and culture. We rather want to tentatively explore how initial success in market making by health economists had substantial consequences for the cultural and political acceptability of competitive behavior by health insurance companies, some of which started to act in ways that deeply undermined the enactment of solidarity among the insured, in spite of the presence of market devices that were built to safeguard solidarity. If, as in our study, neither economists, nor market devices, nor culture can be mobilized as the factor explaining what makes valuation practices, the question we simply want to raise is this: how can valuation studies contribute to an understanding of making markets that renders shifts like the one we encountered from solidarity to competition come as somewhat less of a surprise?

To address this question, we first outline some of the common responses to the question "what makes a valuation practice?". Then we turn to our case of the substantial changes in the Dutch market for hospital care through the regulation of health insurance, with special focus on the development and use of the risk adjustment system (RAS) which was supposed to ensure that solidarity among the insured would not be at odds with competition between insurers. After this we return to the question of how this case may help the study of market 
valuation proceed beyond the repetitive move of inverting culture and devices as final explanations and what this means for how valuation studies analyzes valuation practices.

\section{Economists, Devices, and Culture in the Study of Market Valuation}

Given the striking omission in the extensive public administration literature of the role of market devices and of economics in policy change, focusing on their role provides an interesting entry point into the debate. Valuation studies has an important contribution to make here to ongoing debates since, as far as devices are addressed in public administration, public policy instruments are generally taken as instrumental; that is, as innocent tools of policy makers that are put to use quite straightforwardly to meet the means formulated by politicians. The same can be said for the role of science: although public administration scholars recognize scientific research as a social practice that contextually and continually comes about in specific historical and linguistic contexts (Fischer 2003; Hajer and Wagenaar 2003; Yanow and Schwartz-Shea 2006), studies on science in policy often focus on the instrumental role of science in policy making, for example in legitimizing democratic decision making under conditions of uncertain knowledge and within changing political systems (Maasen and Weingart 2005: 15; see also Giddens 1994; Hall 1993; Lindblom and Cohen 1979; Weiss 1991 for similar arguments). Pierre Lascoumes and Patrick Le Gales (2007: 2) argue that policy instruments are generally seen "either as a kind of evidence, as a purely superficial dimension ... or as if the questions it raises ... are secondary issues, merely part of a rationality of methods without any autonomous meaning". This instrumental understanding of instruments and economics is hard to reconcile with some empirical studies which show that policy instruments produce their own effects, independently of the intentions of policy makers or politicians.

Scholarship on policy change and public sector reform that finds its inspiration in STS has pointed precisely to the importance of analyzing the role of instruments and economics in market oriented health policy reforms (see e.g. Breslau 2013; Johansson Krafve 2014; Lascoumes and Le Gales 2007; Sjögren and Helgesson 2007; Zeiss and Van Egmond, 2014; Zuiderent-Jerak et al. 2015). Rather than seeing the instruments of policy change as the implementation of policy aims, STS scholars have emphasized that the involvement of economists and their market devices have far-reaching normative implications for what public values are enacted in policy practices. Such scholarship on the 
"performativity" of economics (Barry and Slater, 2002; Callon, 1998; MacKenzie and Millo, 2003) considers economic science not only as a mode of investigation and classification of (social) phenomena such as for example market-ization, rational behavior, and moral hazard, but as an important actor that actively brings these phenomena to life through this investigation and classification. Such embeddedness of economic markets in economics (Callon 1998: 1) approaches economic science and devices as active agents in the construction of markets. This means that market consequences often exceed and change the policy aims, which makes the inclusion of market devices and practices by economists in policy analysis part of a relocation of political discussions from explicit policy processes to scientific and "instrumental" domains. This reloca-tion has consequences for the accountability and legitimacy of political decision making regarding the development of health care markets, and hence calls for more research.

Such research raises questions about the relationship between policy instrumentation, the role of science in the development of policy instruments, and the political rationale that gets enacted in policy programs. It asks such questions as: What market instruments are developed when states change their health care policies toward market -based governance systems? How does economics play a role in this? And as a consequence, what values get enacted in these governance arrangements? Elsewhere we have shown how the iconic story on the construction of the market for strawberries in the Sologne region of France, as told by Marie-France Garcia-Parpet $(1986,2007)$ and retold by Callon (1999), is likely to overstate the agential strength of market devices and economic agents due to a failure "to situate the counselor in a wider range of practices that may have been crucial to allowing this Sologne strawberry market to emerge" (Zuiderent-Jerak 2015: $150)$. But another critique has also surfaced in response to the tendency by some STS scholars to overstate the agency of devices and economic actors. And this brings us to the second strand of valuation studies literature that draws inspiration from economic sociology.

Authors within this sub-field of sociology (e.g. Beckert and Aspers 2011; Fourcade 2011; Lamont 2012) have argued that focusing on the specific role of economists and market devices leaves differences across geopolitical sites of valuation unaddressed. Just as Callon's retelling of the strawberry market may be seen as iconic for the STS-inspired emphasis on devices, Marion Fourcade's thorough study of establishing the economic value of nature can be considered emblematic for studies of geopolitical comparison. Fourcade analyzes how France and the United States dealt differently with attaching a monetary value on 
highly damaging oil spills and asks the question, "why, indeed, did the actual economic measure of 'nature' vary so much across these cases?" (Fourcade 2011: 1724). Comparing how dead seabirds, spoiled beaches, destroyed organisms, and damaged ecosystems resulted in hugely varying monetary valuation in her two sites, she finds that the focus on economics and market devices fails to acknowledge that "economic valuation processes are deeply bound up with other aspects of social organization-notably the law, politics, economic expertise, and environmental knowledge" (ibid.).

Based on the different cultural histories of dealing with attributing monetary value to intangibles in France and the United States, Fourcade argues that economic methods and devices for the valuation of public goods are themselves "the product of very specific social processes that are of great relevance to the 'performed' outcome itself" (ibid.: 1725). The critique by sociologists of economic valuation like Fourcade therefore is that, in answering the question as to what makes valuation practices, STS scholars classically confuse explanans and explanandum: presenting economists and market devices as explanation for market development, STS-inspired valuation studies fails to notice how the specific actions by economists and their devices themselves are in need of explaining. According to scholars within the sociology of economic valuation, studying economists and their devices as explanandum is best done through comparative analysis across both space and time as this helps to show how economists and devices are embedded in the social arrangements that in fact produce them. Summarizing this critique, Fourcade concludes her argument as follows

\footnotetext{
The new techniques did "reassemble the social" all right in ways that were not foreseeable (Latour 2005). Yet ultimately the outcome does resemble the point of departure: the natural sensibility performed in each country remains, by and large, historically consistent ... Legal, economic, and scientific institutions, each following their own logic, still managed to hold together while changing at the same time, doing this in a manner that was neither planned nor a priori determined (indeed the process seen from up close is amazingly chaotic) but still coherent enough that the reproduction of natural sensibilities in each case appears to have been overdetermined from every side. Maybe it is this ineffable sense of coherence and overdetermination that we call "culture." (2011: 1770)
}

On the one hand the thorough case and argument presented by Fourcade are quite convincing and resonate with some of our own critiques of the focus on devices and economists within the social studies of markets (see e.g. Zuiderent-Jerak 2009; Zuiderent-Jerak et al. 2015; see also MacKenzie and Millo 2003). However, presenting a return to institutional logics and cultural determinants as a "next step" 
to redress some of the excessive agency ascribed to devices by some STS scholars does resemble something of a "one step up and two steps back" scholarly move. It brings us back to precisely those factors that those STS scholars tried to move away from and that are in fact beyond the scope of empirical scrutiny: they are "ineffable", after allexcept, perhaps, for an economic sociologist who is able to present them as explanans through the scholarly technique of comparative policy analysis. The response from those STS scholars therefore also seems fairly easy to predict: resorting to "culture" and "social processes" may easily be written off as the same capital confusion of presenting as explanations which sociologists should try to explain. That 'solution' would be seen as little less than practicing "sociology of the social" (Latour 2005), even though its proponents may present themselves as studying the process of "reassembling the social". Such inversions of explanans and explanandum, ad infinitum can hardly be considered generative of anything other than the reproduction of the split between an economic sociological focus on culture and an STS focus on devices; a split that may not lead to much more than quibbles between Culture and Device as in the opening act of this paper, or between their respective "experts". To explore a different potential for valuation studies, we would now like to turn to our study of the development of a market for hospital care in the Netherlands.

\section{Governing Hospital Care through a Health Care Market with Solidarity E/Insured}

Over the past decades, many European countries have reformed (parts of) the public sector with the espoused aim of controlling rising costs in this sector, especially in health care. In 2006, as one of the first countries in the EU the Netherlands introduced a market-based governance arrangement for hospital care in the form of the Health Insurance Act (Zorgverzekeringswet), and with this replaced the system of supply regulation that was in place until then. This Act introduced a manda-tory private insurance scheme for all Dutch citizens, based on the idea of managed or regulated ${ }^{4}$ competition as developed by health economist Alain Enthoven. It stimulates competition between health insurers, health providers, and health users, with a more prominent role for insurance companies to allocate

\footnotetext{
${ }^{4}$ Both terms are used equally throughout different publications and seem to point to the same theoretical concepts. Enthoven consequently uses the term 'managed' competition; in recent years this term seems to have replaced the term 'regulated' competition.
} 
means $^{5}$ (see e.g. Brouwer et al. 2006; Enthoven 2006; Enthoven and Van de Ven 2007; Schut and Van de Ven 2005; Van der Grinten and Kasdorp 1999; Van Hout and Putters 2004). One of the main elements of regulated competition is that insurance companies are given the task of competitive purchasing of high-quality, low-cost health care products on behalf of their insured. They are expected to do this through selective contracting of hospitals. This contrasts with the previous system where patients could decide, together with their referring general practitioner, which hospital to go to. Citizens are expected to choose the insurance company they find does the job of selective contracting in the best way. To avoid adverse selection by insurance companies-that is, cherry picking clients that are expected to have low health costs-insurance companies have an obligation to accept every aspiring client who chooses their insurance package.

In 2001, the Dutch government managed to push through the reform plans quite easily with the presentation of a blueprint for a market-based health insurance system. This should come as a surprise, as this apparently smooth reform decision followed three decades of much political opposition about system change and failed policy proposals. This seemingly rapid alteration invites the scholarly question of understanding how this quite profound policy change was possible. Moreover, with many eyes set on the developments of the Dutch health care sector at large, it raised questions about the kind of market that was created: would the market solution indeed prove a solution for a sector in which conflicting demands-equity, quality, and affordability—all need to be cared for? And more specifically, how could competing health insurers be kept from the tempting market strategy of selecting healthier customers?

Given this concern, one specific economic tool, the risk adjustment system (RAS) gained a prominent place in a market that was to be competitive without compromising solidarity. This article is based on a qualitative case study design in which we reconstruct the development and consequences of the RAS based on interviews and documents, and publication analysis. We chose this qualitative design as it allows for an in-depth study of the process of developing policy instruments and the role of scientific knowledge within it, as proposed by Lascoumes

\footnotetext{
5 This becomes noticeable in a new responsibility of insurance companies to allocate means and to deliver high quality care within a mandatory insurance scheme where consumers have the freedom to choose level of coverage. The Act furthermore consists of the installation of a Health Authority and Inspection Authority, and new contracts and laws that should secure open information exchange and free entrance for providers to the health care market (Enthoven, 2006; Enthoven et al., 2007; Schut and Van de Ven, 2005).
} 
and Le Gales (2007) and Callon (1998); but also because it allows us to address some of our own findings which we could not reconcile with the work of these authors. It also allowed us to study the development of the RAS over an extensive period of time. The RAS was initially seen as forming the heart of the health insurance market, as it was to ensure solidarity, and it was developed by a range of powerful societal actors. The development phase of the case study covered the periods 1999 to 2007 and focused on the development of this system and the way in which the market for health insurance became shaped within this instrument. In total 15 semi-structured interviews with key actors in health economics were conducted between 2004 and 2007, and extensive analysis was performed on relevant documents. ${ }^{6}$ The later use of the system and the action it afforded over time was studied by analyzing op-ed articles by some of the respondents and by studying political action based on policy documents by the Dutch minister of health.

The current marketization of the Dutch health care sector builds upon a trend of economization of the sector that according to some started with the introduction of the Sickness Fund Act (Ziekenfondsbesluit) in 1941, which provided national coverage but also rendered health care calculable as a part of national economics (Van Egmond and Bal 2011). Kasdorp (2004) describes the interpretation of health care in terms of proportion of GNP (gross national product) as an economization of health care. Others see the growing attention of the government to the role of the market as a problem solver during the 1990s as a main form of economization (Van Hout and Putters 2004), when the notion of total control of society had lost the better part of its appeal. In this, the Dutch government emulated discussions in the USA under Reagan and in the UK under Thatcher about the future of the steering role of the government and the extent of the government's tasks (see e.g. Kasdorp 2004; Kickert 2000; Pierson 1994, 2004; Walsh 1995). In 1987 a government white paper ${ }^{7}$ on the future of the Dutch health care system—the Dekker Report-showed the first signs of this New Public Management movement for health care. The content of this policy document was accompanied by a linguistic economization

\footnotetext{
${ }^{6}$ For example minutes of meetings of the research groups and with scientific and policy groups, email correspondence, reports, and literature on health economics and health policy.

7 The chairman of the Dekker committee came from the business community-he was a former CEO of the Philips Company. Two other seats were taken by experts in economics. In the 1980s this was an unparalleled event for the health care sector where chairmen and seats tended to be chosen from people coming from the policy field itself.
} 
with the introduction of general economic language to describe health care. Words that were previously solely associated with economics, such as "clients" and "care products", made previously commonly used terms such as "patients" and "care as a process" appear oldfashioned (Van Hout and Putters 2004: 120). More importantly, these instances of economization of health care enabled health care to become part of the economic debate in general, and more specifically to be thought of and talked about in terms of markets and competition (see e.g. Kickert 2000; Walsh 1995).

Moreover, the adoption of this specific economic view on health care was paralleled by the emergence of health economics as a separate scientific discipline. However, the evolution of health care from a sector to an economization of health care and currently a marketization of health care does not self-evidently follow from these developments, nor is it enabled by the political tide alone. It is enacted also by the emerging role of health economics in developing a specific economic theory for health care and by making tools for constituting policy change toward regulated competition in health care, both in educating people on the specific economic theory for health care, and by building this theory into policy tools. This is where we will now turn.

\section{Health Economics as an Emerging Actor}

The emergence of health economics as a single discipline with strong links to policy making is a trend that has been seen throughout many industrialized countries from the 1970s onwards (see e.g. Hunter 1997; Pierson 1994). As for instance Ashmore et al. (1989: 15) and Croxson (1998) show for the UK in their respective studies, health economics professionalized and gained political influence in the UK in the late 1970s. Likewise, in the early 1980s health economics became institutionalized when two Dutch universities-Maastricht University and Erasmus University Rotterdam-undertook the initiative to develop a curriculum in health care economics and management. Maastricht University set up a new chair in health economics situated in the medical department, and in 1982, the Institute of Health Policy and Management (iBMG) was established at the Erasmus University in Rotterdam. Whereas Maastricht developed a public health oriented curriculum, the iBMG offered an interdisciplinary curriculum based on economics, sociology, law, and public administration. Moreover, in 1983 the Dutch-Flemish Health Economics Association was founded. Since 1996, a growing number of health economists have attended the international Health Economics Association (iHEA) conferences (co)organized by the Dutch-Flemish Health Economics Association 
(Rutten 2004). From the 1990s onward, a number of Dutch handbooks on economics and health care issues appeared, as well as publications in newly founded scientific journals on health economics and related subjects. ${ }^{8}$ Thus, over twenty years health economics has grown into an institutionalized and respected scientific discipline.

In this expanding discipline, the development of an economic language for health care paralleled the development of a new theory for a Dutch market for health care, based on Enthoven's theory of managed competition in health care. One of the founders of the iBMG for example had spent time as a visiting research associate at the RAND Corporation in California where he became acquainted with the theory of managed competition for health care. This was based on the work of Enthoven and drew upon earlier work by Kenneth Arrow (interview Van de Ven, April 25, 2006), and developed this theory for the Dutch state of affairs.

This theory on managed competition in health care has been taught to iBMG students since the 1980s. Since then, health economists have educated an increasing number of students on health economics and managed competition (Moen 1989: 63). The iBMG currently employs about 90 health economists as well as a significant number of health policy scientists and health sociologists, and educates an increasing number of students each year. Consequently, the iBMG and its graduates have been actively involved in discussions concerning the market idea as a workable system for the governance of public health care and in the development, use, and distribution of economic theories regarding competition in health care.

The consequences of the increased legitimacy of health economics in discussing and shaping the Dutch practice of regulated competition is shown through an influential "manifesto" (iBMG 2002). In this report the Rotterdam-based health economists firmly explained what policy elements (or policy instruments) were, in their view, still needed to create a fair market in the health care sector. Here, health economists present themselves as "speaking truth to power", as independent scientists. However, more often the influence health economists have on policy remains rather invisible, for example by appearing mostly in the references in government white papers, or as members of scientific committees that advise policy makers. A good example of the apparently distanced but essential role is the involvement of iBMG health economists as independent scientific experts for the evaluation of the health insurance and the care gratuity laws

${ }^{8}$ For example the Journal of Health Economics published by Elsevier since 1982. The first international Handbook of Health Economics by Cuyler and Newhouse was published only in 2005 . 
(ZonMw 2009). The complexity of the new health insurance system, developed by health economists, by that time required academically trained health economists to evaluate its effects. Naturally, the health economists were chosen as independent experts to provide the evaluation with the necessary objectivity. However, with their evaluation and advice these experts did influence a posteriori health policy and the shaping of the health insurance sector.

\section{Building a Device for Managing Solidarity: The Risk Adjustment System}

The political possibility of competition in health care started with the availability of the (aforementioned) theory of a market that ensured solidarity and which was developed by health economists. The active engagement of economists with governance arrangements for health care is, however, also visible in other ways besides theory development, health economics education, and evaluating current policy. Health economists also developed several policy instruments to create a regulated market that would facilitate selective contracting of hospitals by insurance companies without those companies selecting more profitable and discouraging more expensive clients. Such cherry picking, better known as adverse selection in health economics terms, would jeopardize solidarity and needed to be prevented not just through ethical principles but especially through market infrastructures.

As mentioned, the theory of managed competition was introduced in the Netherlands by health economists Van de Ven, Rutten, and Van Vliet. Many of their articles published in leading (Dutch) journals on economics, statistics, and health care in the early 1980s laid out a blueprint for a market-based system that would ensure solidarity in health care (see e.g. Rutten and Van de Ven 1985; Van de Ven 1985). They argued that health care markets differed from other markets, such as the market for jogging shoes-or cars-according to economists (Arrow 1963; Enthoven 1988, 2006), because of the many uncertain factors in this market. ${ }^{9}$ Price mechanisms that regulate "normal" markets therefore supposedly play a minor role in the healthcare market (Arrow 1963; Enthoven 1988; Lapré 2004). In economic theory, these uncertain conditions and lack of effective price mechanisms effectuate a higher consumption in health care-an effect known as moral hazard or government failure. Moreover, health

\footnotetext{
${ }^{9}$ Uncertain factors are for example fluctuations in demand for health care as well as the amount and length of health care needed; other uncertain factors are unexpected technological and demographic developments that influence demand in health care (see for example Arrow 1963; Enthoven 1988; Lapré 2004).
} 
markets also suffer from market failure because: (1) health providers and health insurers have conflicting interests toward health demand and consumption; and (2) doctors are at the same time agents, both for patients and for themselves, while health insurers have to provide good services and make a profit. This mechanism is enhanced by an information asymmetry between patients, doctors, and insurance companies, with the latter trying to avoid contracts with ill persons and the former trying to get a free ride (Arrow 1963; Enthoven 1988; Schut 2003). However, this market failure can, according to economic theory, be controlled by building specific tools to control the behavior of the actors involved in order to secure solidarity. In this way managed competition is an instrument that controls both market failure-quality and accessibility of health care-and government failure-the (in)efficiency and (un)affordability-in health care. Therefore, it could function well to safeguard the politically desired solidarity of the Dutch health system; a remarkable achievement, as it combined marketization with solidarity, two concepts that are usually considered to be in opposition.

At the heart of this fair market lies the tool of risk adjustment. The current Dutch RAS was developed in the 1990s by health economists from the iBMG, the Dutch Ministry of Health, the Association of Dutch Health Insurers (Zorgverzekeraars Nederland $(\mathrm{ZN})$ ), and the Dutch Healthcare Insurance Board (College voor Zorgverzekeraars $(\mathrm{CVZ}))$ in collaboration with a range of research institutes. One of its key components is a fund that is filled by employers and the government by means of the Health Insurance Act. The budget of health insurance companies consists largely of reimbursement from the fund and is complemented by individual premium payments from the insured. The functions of the fund are twofold. First, as an insurance scheme for insurance companies, it settles a large part of the financial differences between insurance companies caused by uneven distribution of predictable costs of medical expenses. In this way, it prevents insurance companies from the potentially negative financial consequences of (accidentally) insuring an unequally high number of people that claim medical expenses in comparison to clients of other insurance companies (Netherlands Bureau for Economic Policy Analysis (CPB) 2006; Schut 2003).

Until 2012, the fund adjusted for risk selection at two points in time; prior to the start of the year (ex-ante), and adjustments made after the year was over to (partly) compensate for losses in that year (ex-post). The fund is also used by insurance companies to set the prices of the insurance schemes for the following year. With these interlinked functions (financial adjustments and price setting), the fund 
"ideally safeguards solidarity in the health insurance market, and protects consumers against adverse risk selection by insurance companies and insurance companies against moral hazard by consumers", according to health economist Van Vliet (interview, 29 May, 2006). The fund therefore has to both enable insurers to act as competitive market actors, selectively contracting hospitals that deliver high-quality care at low cost, and preclude insurers from taking the easier route of adverse selection, leading to profit-maximization through attracting the more profitable clients for their insurance schemes.

Because it brings together opposing behavior of involved actors, the fund is a complex calculative device. It is built upon health indicators in the Netherlands that constitute the main reasons for an individual's health care demand. At the start, in 1993, the risk assessment fund took only two indicators for health use into account: age and gender, as these accounted for 95 percent of the shortages in insurance funds (interview Van Vliet, 29 May, 2006). In later years, the risk adjustment fund was refined by the indicators "region", "medicine use", "diagnosis", and "means of income" (Douven 2005; Van Kleef et al. 2007; interview Van Vliet, 29 May, 2006). Together these indicators add up to about one hundred health indicator groups that determine one's (future) need for medical services and the costs involved in these services. These indicators are based on aggregated medical information taken from many sources such as health insurance companies, health care providers, and related umbrella organizations, health care related non-governmental organizations (NGOs), and Statistics Netherlands. Data are collected from insurance companies, which, according to the international classification of diseases (ICD) coding system, deliver about 170 codes. A committee of health care experts supports the health economists at the iBMG, and critically assesses the codes that represent chronic illnesses. This procedure delivers consented information that is detailed and highly aggregated. However, the refined, and thus more complex, fund controls insurance companies better than the simple fund because insurance companies' claims are subjected to more detailed demands; a claim has to be more precise in its description to receive approval. This should contribute to more fairness as a result.

Ideally, the fund should also function as an incentive for insurance companies to work more efficiently, since profits should come from care that is both of high quality and of low cost. However, this is only the likely route for insurers if the losses due to population differences are fully compensated by the RAS. And in spite of many attempts to improve this system, health economists still consider this complex RAS 
to be selective and imperfect because of a lack of knowledge of some of the reasons why people use health care (Van der Horst et al. 2011). And, as health economists have consistently pointed out, developments outside the Netherlands have shown that imperfect funds, such as in Switzerland, contribute to the unequal treatment of persons within the health market (see for example Van de Ven et al. 2003; Van Kleef et al. 2007). They therefore continue to stress the importance of improving and fine-graining the RAS with increasingly detailed indicators for differences in health costs for different clients. However imperfect at this stage, they still consider this fund the best available option, since it creates a calculative device for the health care market that enables involved actors to talk about and act upon health behavior in terms of risks, while simultaneously attempting to limit market failure.

\section{Construction of an RAS indicator: Future health care use}

But even further detailing of ex-ante risk adjustment leaves some problems unaddressed. A careful analysis of the indicator for "future health care use" reveals, for example, that this indicator is established indirectly, unlike the indicators age and gender. Let us explain: the common way to establish future use of health care is to look at the "current diagnosis" given by doctors to patients. However, it is not immediately obvious how to measure "diagnoses." For example, diagnoses can be measured based on visits to the GP, but can also be measured in other ways based on admissions to a hospital. They can also be based on information from the insurance companies who pay the bills during or after treatment, or on the discharge letter from the hospital after the disease has been treated (interview Van Vliet, 29 May, 2006); Van Kleef et al. 2007). Each option delivers different information. Currently, the data are collected from information about reimbursed diagnoses retained from insurance companies. However, not all diagnoses represent the true illness, and often a diagnosis cannot be given, or is given after treatment just to give it a name or a place in a registration system (Berg 1997; Jerak-Zuiderent and Bal 2011).

The introduction of the Diagnose and Treatment Combinations (DTC) system (a system that resembles Diagnose Related Groups-see for a study of this system Zuiderent-Jerak et al. 2015) further obscures how diagnoses are measured, as DTCs demand translation of illnesses and treatments into well-defined terms, but per definition do not simplify the establishment of the indicator "future use of healthcare". Especially for non-illness related diagnoses, such as treatments needed because of suicide attempts, accidents, and violence, the DTC system delivers problems. 


\section{The RAS Sliding Out of Health Economists' Control}

Given the imperfections of ex-ante risk adjustment, insurance companies that insure a large number of individuals on low income run the risk of having to pay more in reimbursements than could be expected based on the general population. In particular, companies that were previously public insurance companies may have over one million or more insured individuals with low socio-economic status. To alleviate this risk, the RAS until recently also consisted of an ex-post adjustment component. This component initially was introduced to compensate insurance companies for 97 percent of all profits and losses and used to be the core mechanism for risk adjustment, but through the development and improvement of the ex-ante risk adjustment component it has been reduced to 26 percent (Van de Ven 2011).

Risk adjustment afterwards (ex-post), is seen as undesirable by the state and by health economists alike, since it reduces the incentive for insurers to be efficient purchasers of care: some of their losses will be compensated afterwards anyway (Schut and de Wildt 2011). However, the government and health economists differed substantially about the way to address the problem of ex-post risk adjustment-a difference that came to the fore when insurance companies started to display less "regulated" market behavior, for example by acting on the health behavior of the insured individuals, by enlarging the co-payments, from average $€ 150$ per year in 2006 to an average of $€ 350$ per year per insured in 2014, and providing health improvement programs for their insured so that specific groups of patients could be categorized (and prioritized).

In 2010 one of the insurers launched a new brand of insurances that marketed itself exclusively to more highly educated clients. This brand has been growing over the years and has posed serious challenges for those striving for a health care market with solidarity ensured. The business model of this brand is that it tries to attract higher educated clients while discouraging lower educated clients. Through its name, Promovendum, and their logo that reads "insurance for graduates", it tries to appeal to those clients who passed through university education, and although they are obliged through the Health Insurance Act to accept all clients, they have ensured that their questionnaires for applying for their insurance gives potential clients quite a different impression. This insurer can charge a lower insurance premium based on the lower future health care use of their clients, while maximizing profits by not suffering the high and partly uncompensated costs for expensive patients.

Whereas health economists saw this development as an important reminder for the need to improve ex-ante risk adiustment and keep ex- 
post adjustment in place for now, the government wanted to charge ahead on the firmly established road to marketized health care and had quite a different strategy. In contrast to the first evaluation of the new governance arrangement, for which it commissioned the Rotterdam health economists (ZonMw 2009), it commissioned a second evaluation from the commercial consultancy firm PricewaterhouseCoopers (PwC) (Tweede Kamer 2011) and the third one from a similar market player, KPMG Plexus (KMPG Plexus 2014). The second evaluation drew radically different conclusions than the academic health economists had argued for: it stated that the ex-post risk adjustment needed to be abandoned since it was strongly reducing the incentive for insurance companies to efficiently purchase care; that the ex-ante risk adjustment could hardly be improved; and that the risk of adverse selection by insurers was small (as summarized in Van de Ven 2011). To the dismay of health economists, this evaluation no longer needed their advice and expertise, which made it necessary for them to turn to publishing op-ed articles on the pages of health economics and health policy maga-zines and journals and in national newspapers.

The third evaluation (in 2014) drew the conclusion that ex-ante risk adjustment is in need of refinement as the current situation leads to indirect risk selection by insurance companies (for example through supplementary insurances and through the emergence of exclusive labels for students and more highly educated people). Although insurance companies stay within the limits of the law, the risk KPMG Plexus foresaw is a deterioration of trust of the health user in health insurance companies (KPMG Plexus 2014), and thus in the system as a whole. Although the Minister of Health agreed with the recommendations of the research in her letter to Parliament of February 25, 2015, she did not prioritize the issue of improving the RAS. Instead she placed the issue on the research agenda for the following year (Tweede Kamer 2015).

Over time, the limited incentives for insurers to selectively contract hospital care due to the ex-post adjustment of losses started weighing more heavily than concerns about solidarity and the danger of risk selection of clients by insurers. This made competition a more important value for the Dutch minister of health in the making of the Dutch health care market than sticking to the economists' focus of improving risk adjustment to ensure fairness. These (new) different ways of thinking by politicians about health care as an economic market with competition, not fairness, as its main aim in turn (and ironically) marginalized the role of health economists and their market devicesthose very economists and devices that had made the introduction of the health care market possible in the first instance. Showing sensitivity 
to the dangers of adverse selection and moral hazard were still required to obtain political legitimacy for the market development. However, hiring a commercial party like PricewaterhouseCoopers $(\mathrm{PwC})$ or KPMG Plexus to investigate the consequences of minimizing the RAS provided just that legitimacy while equally allowing for new political arguments to include other aims besides solidarity into the policy debate, and to steer policy from its restrictive focus on solidarity toward a more competitively organized health care market. The cumbersome warnings by health economists, including their calls for improved ex-ante risk adjustment, could now be brushed aside as technocratic wishes by an interested party.

These later developments in the Dutch system of regulated competition show that health economists and the market devices they helped to develop by no means proved definitive for the construction of a market that ensured solidarity. But it would seem equally dissatisfying to claim that the good intentions of health economists have been sacrificed to "underlying" cultural, social, or political tendencies that made solidarity doomed to be sacrificed to competition from the start. All political action had initially been geared toward maintaining the long history within the Dutch health care system, and in Dutch health policy, of caring for fair distribution and equal access to public goods within a welfare culture of solidarity. And yet, the presence of certain market arrangements made it possible to move away politically from such a focus on solidarity and to favor competition instead. This makes it a case well worth taking back to the discussion within valuation studies on the question of what makes a valuation practice, and to see what alternative may be emerging to the circular movements of presenting devices or culture as explanans or explanandum.

\section{Conclusions: The Dynamic Intertwinement of Culture and Devices in the Study of Valuation}

In this article, we have investigated the case of an unexpected shift in policy reform in Dutch health care, from a long and persistent focus on solidarity, to favoring competition within market arrangements that were also built to ensure solidarity following policy reform. Asking the question as to what shapes valuation practices we started our study by focusing on the role of economic science in developing market devices. The notion of the performativity of economics did initially seem to offer a suitable way out of a technical or instrumental perception of the role of science in society when analyzing the development of markets for public goods. However, it also became clear that the acting space of health economics and their market devices was becoming auite restricted over time. Market devices therefore turned out to be 
partly unsuccessful in enacting solidarity, at least when one takes into account the tripling of own risk payments and the largely unnoticed increase in risk selection by health insurance companies. But the shift toward competition cannot simply be explained by resorting to "culture" either, as the Netherlands has a long-standing policy commitment to solidarity within welfare arrangements for health care. So where Fourcade focused in her study on establishing the economic value of nature, concluding that the outcome resembled the point of departure, the puzzle we face in our study is precisely the opposite: how to understand economic valuation practices of which ultimately the outcome does not resemble the point of departure?

Some possible explanations from previous STS-inspired work do not seem to quite hold up: we would not feel comfortable in qualifying what happened in the Dutch health care market case as an instance of "counterperformativity", where the "practical use of an aspect of economics make[s] economic processes less like their depiction by economics" (MacKenzie 2007: 55), since that would still ascribe special agential status to the economic theories and devices, whereas those seemed precisely to lose agential strength over time. And yet, the presence of economic theory and market devices to our mind was crucial for the shift to occur.

The changes in the Dutch health care system from a supply regulation system toward a system of regulated competition would have been unthinkable within a welfare state like the Netherlands, had it not been for the RAS, which promised the commensurability of marketized health care and a health case system ensuring solidarity. Right from the moment of introduction, this system framed clients and insurers as protected from each other's bad behavior, preventing it from becoming a market that would suffer from the evils of adverse selection and moral hazard, thereby turning the competitive health care market into a market that ensures solidarity. In that sense, initially the policy change could surely be seen as partly depending on the success of health economics in performing the theory of regulated competition through solidarity-market-devices.

However, these developments in the Dutch health care system over time contributed to different ways of thinking about this market arrangement and the perceived importance of solidarity. Now that at least some form of solidarity was built into the health care market, the problem for politicians had shifted to the fact that insurers were hesitant to purchase care competitively as they could suffer severe reputational damage while any profits would be minimized by the RAS. The resultant policy shift toward less-than-regulated competition through the cancellation of ex-post risk adjustment is hard to imagine 
within the Dutch health care system, which for many years was dominated by a strong commitment to solidarity. The promise of the very notion of "regulated competition" would be that competition and solidarity would be united in a health care markets governance arrangement. Over time, however, the "regulated" part of the notion became less important than the "competition" part and the notions once again proved to be at odds with each other, while the political and policy debate shifted toward favoring the latter over the former. Such a shift however became possible by long-term developments of sliding valuations from solidarity as the prominent aim to competition as the prominent aim-and importantly, this shift only occurred in the political debate once the system of regulated competition had been introduced with devices that promised that competition and solidarity would not be at odds. Without that promise and without the initial development of the RAS, strengthening competition in health care governance at the expense of solidarity may, we feel, have been equal to political suicide for many political parties involved in the introduction of the Health Insurance Act.

This leads us to conclude that, although our work resonates with the critical reading of the performativity thesis as presented by Fourcade, this reading needs to contribute to a more empirically detailed study of how valuations evolve over time. Thereby, notions like "culture" or "institutional logics" do not become ineffable explanations that are extraneous to the empirical study of valuation practices, but become a central part of the phenomena under study. So rather than focusing on how social processes and culture ensure that market valuations ultimately resemble the point of departure, we would like to include how political, social, and cultural processes may well change over time, partly because of the economic devices that make markets. Work in valuation studies allotting devices and social processes a less predictable role in the analysis of valuation studies benefits by bypassing that sticky "social-technical" divide that orders the sociological scholarly debate in rather repetitive ways.

The stakes of such a shift in focus are substantial, we claim. Theoretically, it would seem crucial to prevent that an emerging and creative field like valuation studies merely ends up reproducing age-old deterministic debates about whether technology drives cultures or culture drives technologies (cf. Misa 1994). Critique of such determinism and its overly static understanding of culture has been voiced most clearly by Harald Garfinkel through his classic notion of the "cultural dope". Garfinkel's critique was that much of sociology is guilty of producing the misleading character of "the man-in-thesociologist's-society who produces the stable features of the society by 
acting in compliance with preestablished and legitimate alternatives of action that the common culture pro-vides" (1967: 68). Although it would be an overly critical reading of much of economic sociology to say that studying how valuation practices ultimately resemble the point of (cultural) departure equals reproducing "cultural dopes", Garfinkel's critique surely points to the risk that valuation studies runs by embracing an "ineffable" and static notion of culture. A similar reminder may however be appropriate regarding the focus on devices as an explanans, which has dominated STS contributions to valuation studies. Such a warning can take the shape of what we, paraphrasing Garfinkel, may call the "technical dope". This equally misleading figure resembles "the man-in-STS-scholar's-society who produces the stable features of a valuation practice by acting in compliance with pre-established and legitimate alternatives of action that market devices provide"; and although once again it would be an unfair reading to criticize work on market devices as producing "technical dopes", such critique again points to the risk of embracing an overly static notion of devices and of their agential strength. Inversely, our analysis can also be read-somewhat more cynically-as methodological strategy advice for scholars who are clear about what side of the fence they are sitting on: if you want to stress the importance of devices, do a short-term in-depth case study; for strengthening the importance of culture, carry out an international comparative study, making sure not to compare cases from what could be depicted as the same culture.

Leaving such cynicism aside, studying the dynamic intertwinement between devices and market cultures may well be hugely consequential for what public values become to mean over time. Therefore, a more dynamic study of the role of devices and culture in valuation practices could provide an antidote to the illusion that solidarity in governance arrangements could be assured through market devices or cultures of solidarity alone. This may well give valuations of solidarity a fairer chance as well as preventing those repetitive quibbles between culture and device. Although, whether they will be able to resist... 
Culture: "So here you see it's you who failed!

Without devices, what is 'fair'?!"

Device: "Well how you'd think I'd ever beat The Culture of The Market Square?!"

Culture: "Now don't blame me; the ineffable!

How could an abstraction be to blame?!"

Device: "Well, how mere materiality?!

Welfare's demise bears Culture's name!"

Culture: "With risk assessment poorly built

You gave way to pure politics!”

Device: ...

Culture: "Device? ... Device?!”

Device: "Sorry Culture,

I really don't have time for this.

I have market cultures to make."

Culture: "Get back here!

That's not how I made you!"

Acknowledgements. This article is the result of long-standing research interest by both authors on the role of economics and market devices in the making of health care markets. The case study was carried out by Stans van Egmond and funded by the Institute of Health Policy and Management of the Erasmus University Rotterdam. The authors wish to thank the respondents for their participation and Roland Bal, Hester van de Bovenkamp, Ivanche Dimitrievski, Kor Grit, ClaesFredrik Helgesson, Lotta Björklund Larsen, John Law, Johan Nilsson, and Steve Woolgar, and two anonymous reviewers for their helpful comments on an earlier draft of this article. Laura Watts has contributed to this paper in crucial yet unforeseen ways. Earlier versions of this article were presented during the Health Care Governance seminar at the institute for Health Policy and Management of the Erasmus University Rotterdam and the ValueS: Science, Technology and Valuation Practices seminar at Tema TTechnology and Social Change at Linköping University. 


\section{References}

Arrow, Kenneth. 1963. "Uncertainty and the Welfare Economics of Medical Care." The American Economic Review 53 (5): 941-973.

Ashmore, Malcolm, Mike Mulkay, and Trevor Pinch. 1989. Health and Efficiency. A Sociology of Health Economics. Milton Keynes: Open University Press.

Balle Hansen, Morten, and Jorgen Lauridsen. 2004. “The Institutional Context of Market Ideology: A Comparative Analysis of the Values and Perceptions of Local Government CEOs in 14 OECD Countries.” Public Administration 82 (2): 491-524.

Barry, Andrew, and Don Slater. 2002. "Introduction: The Technological Economy.” Economy and Society 31 (2): 175-193.

Beckert, Jens and Patrik Aspers, eds. 2011. The Worth of Goods; Valuation and Pricing in the Economy. Oxford: Oxford University Press.

Berg, Marc. (1997) Rationalizing Medical Work: Decision-Support Techniques and Medical Practices. Cambridge, MA: MIT Press.

Bijker, Wiebe E. 1995. Of Bicycles, Bakelites and Bulbs: Towards a Theory of Sociotechnical Change. Cambridge, MA: MIT Press.

Boltanski, Luc and Eve Chiapello. 2005. The New Spirit of Capitalism. London and New York: Verso.

Breslau, Daniel 2013. "Designing a Market-like Entity: Economics in the Politics of Market Formation." Social Studies of Science 43 (6): 829-851.

Brouwer, Werner, Job Van Exel, Pieter Van Baal, and Johan Polder. 2006. "Economics and Public Health: Engaged to Be Happily Married!" European Journal of Public Health 17 (2): 122-124.

Callon, Michel 1998, ed. The Laws of the Markets. Oxford: Blackwell. 1999. "Actor-network Theory; The Market Test." In Actor Network Theory and after, edited by John Law and John Hassard, 181-195. Oxford: Blackwell.

Callon, Michel, Yuval Millo, and Fabian Muniesa, eds. 2007. Market Devices. Oxford: Blackwell.

CPB. 2006. "Memorandum 149. Zorg in Model: Algemene Structuur En Varianten." The Hague: Centraal Planbureau.

Croxson, Bronwyn. 1998. "From Private Club to Professional Network: An Economic History of the Health Economists' Study Group, 1972-1997." Health Economics 7 (Suppl 1): S9-45).

Dekker, Commissie. 1987. "Bereidheid Tot Verandering." The Hague: Distributiecentrum Overheidspublicaties.

Douven, Rudy. 2005. "Kwaliteit Risicoverevening Hangt Af Van Marktontwikkelingen.” ESB 90 (4465): 290-292.

Dussauge, Isabelle, Claes-Fredrik Helgesson, and Francis Lee, eds. 2015. Value Practices in the Life Sciences and Medicine. Oxford: Oxford University Press.

Enthoven, Alain. 1988. Theory and Practice of Managed Competition in Health Care Finance. Amsterdam: Elsevier. 
2006. "Consumer Choice of Health Plan. Connecting Consumers and Providers in Systems." VGE Congres, "Consumer choice in de zorg: De juiste keuze?” [Conference of the Dutch Society for Health Economics "Consumer choice in health: The right choice?"]. Rotterdam, November.

Enthoven, Alain, and Wynand Van de Ven. 2007. "Going Dutch-ManagedCompetition Health Insurance in the Netherlands." New England Journal of Medicine 357 (24): 2421-2423.

Fischer, Frank. 2003. "Beyond Empiricism: Policy Analysis as Deliberative Practice." In Deliberative Policy Analysis: Understanding Governance in the Network Society, edited by Maarten Hajer and Hendrik Wagenaar, 209-227. Cambridge: Cambridge University Press.

Fourcade, Marion. 2011. "Cents and Sensibility; Economic Valuation and the Nature of 'Nature'." American Journal of Sociology 116 (6): 1721-1777.

Garcia, M.-F. 1986. "La construction sociale d'un marché parfait: le marché au cadran de Fontaines-en-Sologne." Actes de la Recherche en Sciences Sociales 65: 2-13.

Garcia-Parpet, Marie-France. 2007. "The Social Construction of a Perfect Market; The Strawberry Auction at Fontaines-en-Solonge." In Do Economists Make Markets? On the Performativity of Economics, edited by Donald MacKenzie, Fabian Muniesa, and Lucia Siu, 20-53. Princeton, NJ: Princeton University Press.

Garfinkel, Harold. 1967. Studies in Ethnomethodology. Englewood Cliffs, NJ: Prentice-Hall.

Giddens, Anthony. 1994. Beyond Left and Right. The Future of Radical Politics. Cambridge: Polity Press.

Hajer, Maarten, and Hendrik Wagenaar, eds. 2003. Deliberate Policy Analysis: Understanding Governance in the Network Society. Cambridge: Cambridge University Press.

Hall, Peter. 1993. "Policy Paradigms, Social Learning, and the State: The Case of Economic Policy Making in Britain." Comparative Politics 25: 275296.

Hughes, Thomas. 1994. “Technological Momentum.” In Does Technology Drive History? The Dilemma of Technological Determinism, edited by Merritt Roe Smith, and Leo Marx, 101-114. Cambridge: MIT Press.

Hunter, David . 1997. Desperately Seeking Solutions. Rationing Health Care. Harlow: Pearson Education.

— 2005. “The National Health Service 1980-2005.” Public Money \& Management 25: 209-212.

Institute for Health Policy and Management (iBMG) 2002. Manifest, Twintig Zorgpunten over Het Toekomstige Zorgstelsel. Rotterdam: iBMG.

Jasanoff, Sheila. 2004. “Ordering Knowledge, Ordering Society.” In States of Knowledge: The Co-production of Science and Social Order, edited by Sheila Jasanoff, 13-45. London: Routledge.

Jerak-Zuiderent, Sonja, and Roland Bal. 2011. "Locating the Worths of Performance Indicators; Performing Transparencies and Accountabilities in Health Care." In The Mutual Construction of Statistics and Society, 
edited by Ann Rudinow Sætnan, Heidi Mork Lomell, and Svein Hammer, 224-244. London and New York: Routledge.

Joerges, Bernward. 1999. "Do Politics Have Artefacts?" Social Studies of Science 29 (3): 411-431.

Johansson Krafve, Linus. 2014. "Marketization by the (Rule)book: Concern for Market and Public Values in Primary Care." In Concerned Markets: Economic Ordering for Multiple Values, edited by Susi Geiger, Debbie Harrison, Hans Kjellberg, and Alexandre Mallard, 46-71. Cheltenham: Edward Elgar Publishing.

Kasdorp, Jan. 2004. "Rivaliserende waarden, eisen en wensen in de gezondheidszorg." Beleid en Maatschappij, tijdschrift voor beleid, politiek en maatschappij 31 (4): 211-221.

Kickert, Walter. 2000. Public Management Reforms in the Netherlands: Social Reconstruction of Reform Ideas and Underlying Frames of Reference. Delft: Uberon.

KPMG Plexus 2014. Evaluatie Zorgverzekeringswet. Maarssen: KPMG Plexus.

Lamont, Michele. 2012. "Toward a Comparative Sociology of Valuation and Evaluation." Annual Review of Sociology 38 (1): 201-221.

Lapré, Ruud. 2004. "Health Economics in the Netherlands: The Beginning." In Health Economics. Adding Value to Health Care? edited by Werner Brouwer, Richard Janssen, and David Larmuseau, 69-76. Rotterdam: Dutch-Flemish Health Economics Association.

Lascoumes, Pierre, and Patrick Le Gales. 2007. "Introduction: Understanding Public Policy through Its Instruments.” Governance: An International Journal of Policy, Administration, and Institutions 20 (1): 1-21.

Latour, Bruno. 2005. Reassembling the Social: An Introduction to ActorNetwork-Theory. Oxford: Oxford University Press.

Lindblom, Charles E., and David K. Cohen. 1979. Usable Knowledge: Social Science and Social Problem Solving. New Haven, CT: Yale University Press.

Maasen, Sabine, and Peter Weingart. 2005. "What's New in Scientific Advice For Politics?" In Democratization of Expertise? Exploring Novel Forms of Scientific Advice in Political Decision-Making, edited by Sabine Maasen, and Peter Weingart, 153-169. Dordrecht: Springer.

MacKenzie, Donald. 2007. "Is Economics Performative? Option Theory and the Construction of Derivatives Markets." In Do Economists Make Markets? On the Performativity of Economics, edited by Donald MacKenzie, Fabian Muniesa, and Lucia Siu, 54-86. Princeton, NJ: Princeton University Press.

MacKenzie, Donald, and Yuval Millo. 2003. "Constructing a Market, Performing Theory: The Historical Sociology of a Financial Exchange." American Journal of Sociology 109 (1): 107-145.

MacKenzie, Donald, Fabian Muniesa, and Lucia Siu, eds. 2007. Do Economists Make Markets? On the Performativity of Economics. Princeton, NJ, Princeton University Press. 
Misa, Thomas J. 1994. "Retrieving Sociotechnical Change from Technological Determinism." In Does Technology Drive History? The Dilemma of Technological Determinism, edited by Merritt Roe Smith, and Leo Marx, 115-141. Cambridge, MA: MIT Press.

Moen, Jan. 1989. Innovatie in Universitair Onderwijs. Organisatie-En Curriculumontwikkeling in Een Nieuwe Universitaire Opleiding. Rotterdam: Erasmus University.

Netherlands Bureau for Economic Policy Analysis (CPB). 2006. "Memorandum 149. Zorg in Model: Algemene Structuur En Varianten.” The Hague: CPB.

Pierson, Paul. 1994. Dismantling the Welfare State? Reagan, Thatcher, and the Politics of Retrenchment. Cambridge: Cambridge University Press. 2004. Politics in Time. History, Institutions, and Social Analysis. Princeton, NJ and Oxford: Princeton University Press.

Porter, Michael E., and Elizabeth Olmsted Teisberg. 2004. "Redefining Competition in Health Care." Harvard Business Review 65-76.

Ranade, Wendy. 1995. "The Theory and Practice of Managed Competition in the National Health Service." Public Administration 73 (2): 241-262.

Rutten, Frans. 2004. "The Nineties." In Health Economics. Adding Value to Healthcare?, edited by Werner Brouwer, Richard Janssen, and David Larmuseau, 57-60. Rotterdam: Erasmus University.

Rutten, Frans and Wynand van de Ven. 1985. "Concurrentie tussen hulpverleners in de gezondheidszorg." Economisch Statistische Berichten 70: 521-525.

Schut, Erik. 2003. "De zorg is toch geen markt? Laveren tussen marktfalen en overheidsfalen in de gezondheidszorg" [Health isn't a market? Between market failure and government failure]. Inaugural Speech. Rotterdam: Erasmus University.

Schut, Erik and Jan Erik de Wildt. 2011. "Risicoverevening: hoe zit het nu precies?” De Eerstelijns 4 (mei): 10-11.

Schut, Erik and Wynand van de Ven. 2005. "Rationing and Competition in the Dutch Health Care System." Health Economics 14: 59-74.

Sjögren, Ebba and Claes-Fredrik Helgesson 2007. "The Q(u)ALYfying Hand; Health Economics and Medicine in the Shaping of Swedish Markets for Subsidized Pharmaceuticals." In Market Devices edited by Michel Callon, Yuval Millo, and Fabian Muniesa, 215-240. Oxford: Blackwell.

Tweede Kamer [The House of Representatives of the Netherlands]. 2011. Internationale kwalitatieve evaluatie risicoverevening, bijlage bij de brief van Minister Schippers aan Tweede Kamer [International qualitative evaluation risk adjustment, appendix to the letter by Minister Schippers to the House of Representatives]. TK 3046061.

- 2015. Herziening Zorgstelsel. Kst-29689-591, 2015. Brief van de Minister van Volksgezondheid, Welzijn en Sport [Revision of Health System. Letter from the Minister of Health, Welfare and Sports]. TK 29689-591. 
Van de Ven, Wynand. 1985. "Gereguleerde competitie in de gezondheidszorg." Liberaal Reveil 26 (1): 7-13.

-.2011. “Risicoverevening nog niet op orde.” ESB 96 (4607): 221.

Van de Ven, Wynand, Konstantin Beck, Florian Buchner, Dov Chernichovsky, Lucien Gardiol, Alberto Holly, et al. 2003. "Risk Adjustment and Risk Selection on the Sickness Fund Insurance Market in Five European Countries." Health Policy 65: 75-98.

Van der Grinten, Tom, and Jan Kasdorp. 1999. "Choices in Dutch Health Care: Mixing Strategies and Responsibilities." Health Policy 50: 105-122.

Van der Horst, Albert, Frank van Erp, and Jasper de Jong. 2011. "Trends in gezondheid en zorg." CPB Policy Brief 2011/11.

Van Egmond, Stans, and Roland Bal. 2011. "How to Model a Medical Specialist, Modeling Dutch Health Care: Boundary Configurations in Science-Policy Relations." Science Technology and Human Values 36 (1): 108-130.

Van Hout, Eelco and Kim Putters. 2004. "The Value of Norms." In Economisering van zorg en beroepsethiek [Economisation of healthcare and professional ethics], 113-162. Zoetermeer: Centrum voor Ethiek en Gezondheid/Raad voor Volksgezondheid en Zorg.

Van Kleef, Richard, Konstantin Beck, Wynand van de Ven, and René van Vliet. 2007. "Does Risk Equalization Reduce the Viability of Voluntary Deductibles?" International Journal of Health Care Finance and Economics 7: 43-58.

Walsh, Kieron. 1995. Public Services and Market Mechanisms. Competition, Contracting and the New Public Management. London: Macmillan.

Weiss, Carol. 1991. "Policy Research: Data, Ideas, or Arguments?" In Social Sciences and Modern States, edited by Peter Wagner, 307-332. Cambridge: Cambridge University Press.

Winner, Langdon. 1980. “Do artifacts have politics?” Daedalus 109 (1): 121-136.

Woolgar, Steve, and Geoff Cooper. 1999. "Do Artefacts Have Ambivalence? Moses' Bridges, Winner's Bridges and other Urban Legends in S\&TS." Social Studies of Science 29 (3): 433-449.

Yanow, Dvora, and Peregrine Schwartz-Shea. 2006. Interpretation and Method. Empirical Research Methods and the Interpretive Turn. London: Scharpe.

Zeiss, Ragna, and Stans van Egmond. 2014. "Dissolving Decision Making? Models and Their Roles in Decision-Making Processes and Policy at Large." Science in Context 27: 631-657.

ZonMw. 2009. Evaluatie Zorgverzekeringswet en de wet op de zorgtoeslag. The Hague: ZonMw.

Zuiderent-Jerak, Teun. 2009. "Competition in the Wild: Reconfiguring Health Care Markets.” Social Studies of Science 39 (5): 765-792.

- 2015. Situated Intervention; Sociological Experiments in Health Care. Cambridge, MA: MIT Press. 
Zuiderent-Jerak, Teun, Kor Grit, and Tom van der Grinten. 2015. "Critical Composition of Public Values; On the Enactment and Disarticulation of What Counts in Healthcare Markets. In Value Practices in the Life Sciences and Medicine, edited by Claes-Frederik Helgesson, Francis Lee, and Isabelle Dussauge, 119-135. Oxford: Oxford University Press.

Teun Zuiderent-Jerak is LiU Research Fellow at the Department of Thematic Studies-Technology and Social Change of Linköping University, Sweden. His research focuses on standardization and quality improvement practices in healthcare, the construction of markets for public values, and sociological research that explicitly aims to intervene in the practices it studies. He has published in the British Medical Journal, BMJ Quality and Safety, BMC Medical Research Methodology, Health Care Analysis, Health Economics, Policy and Law, Health Expectations, Health Policy, HumanComputer Interaction, Science as Culture, Science, Technology, and Human Values, Social Science \& Medicine, and Social Studies of Science. His book Situated Intervention; Sociological Experiments in Health Care was published this year by the MIT Press.

Stans van Egmond is Director of the Dutch Thrombosis Foundation since November 2015. Previously, she worked as senior researcher at the Rathenau Institute on patient autonomy and technology, after having completed her thesis in 2010 on the construction and development of health economics in the Netherlands at the Institute of Health Policy and Management in Rotterdam. She has published in Science in Context, Science Technology and Human Values, Evidence \& Policy, and Science Studies. Recent books include Sterke Verhalen uit het Ziekenhuis (Narratives on hospital care) on patient autonomy, published by the Rathenau Institute in 2014, and De Meetbare Mens (Quantified health) on practices of quantification in health care, forthcoming in 2015 by the Rathenau Institute. 